\title{
Experimental studies on the life cycle of Jassa falcata (Crustacea, Amphipoda)
}

\author{
K. K. C. NAIR ${ }^{1} \&$ K. Anger ${ }^{2}$ \\ ${ }^{1}$ National Institute of Oceanography, Regional Centre; \\ Cochin 682 018, Kerala, India, \\ and \\ ${ }^{2}$ Biologische Anstalt Helgoland (Meeresstation); \\ D-2192 Helgoland, Federal Republic of Germany
}

\begin{abstract}
Jassa falcata (Leach), an unselective suspension feeder, was cultivated in standing, unaerated finger bowls, feeding on a mixture of Brachionus plicatilis, Scrippsiella faeroense, Ulva spec., and natural detritus. This amphipod can also be maintained with diets composed of dead or live material of both plant and animal origin, but an addition of living zooplankton is necessary for longterm cultivation. Starvation resistance is higher in females than in males, and it is increased by lower temperatures. The life span of $J$. falcata increases with decreasing temperature, and it is generally higher in females (maximum: 252 days at $10^{\circ} \mathrm{C}$ ) than in males. In laboratory culture, a bimodal mortality pattern is typical with high juvenile death rates, low mortality during the reproductive phase, and again increasingly high death rates toward the end of the life cycle. Growth rate depends on temperature, sex, and individual age. The temperature dependence of growth is particularly high in males, and it is higher in adults than in juveniles. The total number of moults is lower in males (5 to 6$)$ than in females ( 7 to 9). Sexual maturity is attained at moult IV to $\mathrm{V}$. The average incubation time of eggs is about 9 to 16 days (highest value at $10^{\circ} \mathrm{C}$ ). Three to 4 broods were observed, with largest numbers of offspring at $10^{\circ} \mathrm{C}$.
\end{abstract}

\section{IN'TRODUCTION}

The marine amphipod Jassa falcata (Leach) has an almost cosmopolitan distribution (Schellenberg, 1942). It prefers biotopes governed by strong currents (Ebling et al., 1948; Daro, 1970; Perkins, 1974), and is a dominant species in polluted harbours (Barnard, 1958). Frequently it occurs in extremely dense populations, often associated with Corophium insidiosum (e. g. Helgoland, North Sea: Sokolowsky, 1900; Belgium: Daro, 1970; American Pacific coast: Ricketts \& Calvin, 1968). Population densities of 11.000 to 72.000 individuals $\mathrm{m}^{-2}$ were encountered in exposed epifaunal communities off Helgoland; juvenile individuals occurred frequently in the plankton around the island.

In spite of this obvious ecological importance of $J$. falcata, very little is known about the biology and autecology of this species. Ricketts \& Calvin (1968) state: "The amphipods are one of the most abundant, and at the same time least-known, populations of our intertidal fauna". 
The present paper reports on some observations on nutrition, starvation resistance, and behaviour of $J$. falcata. The description of the life cycle in laboratory culture comprises data on growth, fecundity, and life span under three different environmental temperatures.

\section{MATERIAL AND METHODS}

Living material was collected by means of scraping epifauna from the surface of jetties and buoys at Helgoland Harbour (North Sea). Individuals of Jassa falcata were sorted out and kept in aquaria.

Before attempting the cultivation of $J$. falcata in the laboratory, different food mixtures were tested for their suitability: Brachionus plicatilis (rotifer), given exclusively or in combination with living algae (Ulva spec., Porphyra spec.), with natural detritus or ground dried algae (Ceramium spec., Ulva spec.); algal powder exclusively (Ulva spec., Porpbyra spec., Ceramium spec.); detritus exclusively; phytoplankton (Scrippsiella faeroense). These food items were obtained and treated as recently described by Nair \& Anger (1979). A total of 420 individuals of $J$. falcata was subdivided into three major size groups: adults ( 8 to $13 \mathrm{~mm}$ ), medium-sized ( 4 to $7 \mathrm{~mm}$ ), and juvenile (below $3 \mathrm{~mm}$ ). The amphipods were introduced in small groups into glass bowls, each containing $300 \mathrm{ml}$ of unaerated sea water, and provided with the food to be tested. Water and food were changed every third day. The survival rates after a period of 30 days served as an index of food value.

Average ingestion rates of $J$. falcata were determined in preliminary experiments; two different prey organisms were offered: Brachionus plicatilis and nauplii of Artemia salina. For each experiment 20 adult amphipods were introduced into bottles filled with $250 \mathrm{ml}$ of sea water. At 6-h intervals, prey concentrations were determined in experimental and control bottles. Ingestion rates were calculated from the differences observed over a period of 24 h.

Approximate digestion rates were studied in a separate experiment: 40 adult $J$. falcata ( 6 to $9 \mathrm{~mm}$ ) of both sexes were starved for $24 \mathrm{~h}$, and then placed individually in separate finger bowls containing sea water with mixed food (Brachionus plicatilis and algal powder). Observations were made at $1-\mathrm{h}$ intervals, and the time at which the first faecal pellet appeared was noted.

The survival time of $J$. falcata under starvation was tested in both sexes and at two different temperatures $\left(10^{\circ}\right.$ and $\left.15^{\circ} \mathrm{C}\right)$. For each experiment 20 individuals were maintained individually in sea water without food. Mortality rates were recorded daily; water was changed every second day.

As a standard combination of food the same mixture was used as had been found suitable for C. insidiosum (Nair \& Anger, 1979): Brachionus plicatilis (60\% by volume), powdered Ulva spec. (30\%), natural detritus (5\%), and Scrippsiella faeroense (5\%). Cultivation of $J$. falcata, was initiated with 30 ot and 30 o $q$ collected in the field. They were introduced by pairs into finger-bowls with $100 \mathrm{ml}$ of sea water $\left(20^{\circ} \mathrm{C}\right)$. After about 30 days most of the females carried eggs. For cultivation, only juveniles were used which had been liberated on the same day. They were raised in groups of 6 to 8 individuals per bowl under three different constant temperature regimes: $10^{\circ}, 15^{\circ}$, and $20^{\circ} \mathrm{C}$. After the first 
moult, the sexual differences became apparent. One male and one female were then kept in each bowl for further observation.

A dissecting microscope with an eye piece micrometer was employed for observations and measurements in live amphipods. Body size was measured as distance from the tip of the rostrum to the end of the telson.

If not stated otherwise, experimental temperature was $15^{\circ} \pm 1{ }^{\circ} \mathrm{C}$, salinity 29 to $33 \%$ (mean: $32 \%$ ), pH 7.8 to 8.4 (mean: 8.1 ). The sea water was filtered (Millipore membrane filter; $0.4 \mu \mathrm{m}$ pore size). The experiments were carried out under a $12: 12-\mathrm{h}$ photoperiod using artificial light from a 40-W daylight neon lamp.

\section{RESULTS}

\section{Food uptake}

Jassa falcata is a typical suspension feeder. If there is directed water movement, it faces the current and directs suspended particles by means of its strongly setosed antennae and the first gnathopods to the mouth parts; beating of pleopods is weak.

In experimental bowls it enhances the respiratory and feeding current by splashing faster with its pleopods. In this way it actively moves particles to the reaches of its antennae, from where prey can be gathered. Cannibalism was often observed, especially if too little food was offered.

The comparison of ten different diets revealed that $J$. falcata is an omnivorous particle feeder. It can utilize live and dead material of both plant and animal origin. However, there are marked differences in food value: The rotifer Brachionus plicatilis, provided exclusively or in combination with natural detritus or living algae (Ulva spec., Porphyra spec.), is most nutritious (low mortality over one month observation period in all size groups).

When algal powder (same species as above), natural detritus, or the flagellate Scrippsiella faeroense was given as food, markedly higher mortalities occurred. Except Ulva powder, these foods are well utilized by juveniles, but much less by medium-sized and adult amphipods.

Powdered Ceramium thalli proved to be poisonous to $J$. falcata when they are decaying: All animals (all size-classes, both sexes) died during the tests. This held true even if the algal matter was mixed with $B$. plicatilis. A mixture of rotifers with Ulva powder, flagellates, and detritus gave best results; therefore it was used as standard diet for all size groups in later experiments.

Ingestion rates of adult $J$. falcata feeding on $B$. plicatilis and on Artemia salina nauplii were determined in separate preliminary experiments: In one type of experiment, water and food were renewed when prey concentrations were determined every $6 h$; in parallel experiments the initial water and food were used for $24 \mathrm{~h}$. The average ingestion rates in the first case varied from 2.7 to 4.3 rotifers per individual $\mathrm{h}^{-1}$, and from 1.2 to 2.5 nauplii per individual $\mathrm{h}^{-1}$, respectively. The feeding rates were influenced neither by the duration of the experiment nor by presence or absence of light.

In the second type of experiment, almost identical ingestion rates compared with the first one were observed when $A$. salina nauplii were given as prey. When $B$. plicatilis was 
provided, ingestion rate decreased continuously from 3.5 rotifers per individual $\mathrm{h}^{-1}$ to almost zero at the end of the experiment (after $24 \mathrm{~h}$ ).

\section{Digestion rate and starvation}

In order to determine the time needed to digest the food taken up by Jassa falcata, the average time between the beginning of feeding in Brachionus plicatilis and algal powder (Ulva spec.) and the first appearance of faecal pellets was measured at $15^{\circ} \mathrm{C}$. Defecation begins 4 to $9 \mathrm{~h}$ after food intake; $50 \%$ of all individuals were found to have defecated for the first time after $6.5 \mathrm{~h}$. In contrast to Coropbium insidiosum (Nair \& Anger, 1979) no differences in the digestion rate between males and females were observed.

Maximal survival time during starvation was observed in 80 adult individuals at $10^{\circ}$ and $15{ }^{\circ} \mathrm{C}$. This measure for starvation resistance suggests that males are more sensitive than females, and both sexes can withstand longer starvation periods at lower than at higher temperatures. The maximal values observed at the two temperatures were 16 and 20 days in males, but 20 and 25 days in females.

\section{Life span and mortality}

Increasing temperature reduces significantly the life span of Jassa falcata (Table 1): There is a considerable difference in length of life between $10^{\circ}$ and $15^{\circ}$, it is less marked between $15^{\circ}$ and $20^{\circ} \mathrm{C}$. Over the whole temperature range $\left(10^{\circ}\right.$ to $\left.20^{\circ} \mathrm{C}\right)$ the maximum life span is reduced by $39 \%$ in both sexes. In all experiments, females lived on average 2.4 to $3.6 \%$ longer than males (Table 1 ).

The mortality pattern in a laboratory population of Jassa falcata is obviously independent of external factors such as temperature: There is high mortality (10 to $50 \%)$ in juvenile stages (especially during the time of the first, maximally until the third moult), rather low mortality during the reproductive phase, and increasingly high mortality in the last weeks of the total life span (especially during the last two moults).

\section{Growth and moulting rate}

Growth rates in amphipods can be measured as (1) average length increment in body size per day; (2) average length increment per moult; (3) increase in number of antennal segments.

Length increment in body size per day is strongly influenced by temperature; it also depends on individual age and sex (Table 1). From the first to the fourth moult, growth rate is generally higher than at later stages. This asymptotic growth pattern is particularly distinct at lower temperatures.

Males grow faster than females at all stages of life and at all temperatures compared, and both sexes show increasing growth rates with increasing temperature (Table 1). The 
Table 1

Jassa falcata: Survey of the most important life-cycle data at different temperatures

\begin{tabular}{|c|c|c|c|c|}
\hline Life-cycle criteria & & $10^{\circ}$ & $15^{\circ}$ & $20^{\circ} \mathrm{C}$ \\
\hline Maximal life span (days) & $\begin{array}{l}\delta \\
\wp\end{array}$ & $\begin{array}{l}246 \\
252\end{array}$ & $\begin{array}{l}167 \\
173\end{array}$ & $\begin{array}{l}149 \\
153\end{array}$ \\
\hline Maximal number of moults & $\begin{array}{l}\partial \\
q\end{array}$ & $\begin{array}{l}6 \\
9\end{array}$ & $\begin{array}{l}6 \\
9\end{array}$ & $\begin{array}{l}5 \\
7\end{array}$ \\
\hline Maximal body length (mm) & $\begin{array}{l}0 \\
\wp\end{array}$ & $\begin{array}{l}8.9 \\
8.2\end{array}$ & $\begin{array}{l}7.8 \\
7.0\end{array}$ & $\begin{array}{l}8.0 \\
7.3\end{array}$ \\
\hline $\begin{array}{l}\text { Growth (mm per moult): } \\
\text { moult I to IV }\end{array}$ & $\begin{array}{l}\hat{0} \\
\text { q }\end{array}$ & $\begin{array}{l}1.45 \\
1.35\end{array}$ & $\begin{array}{l}1.12 \\
0.95\end{array}$ & $\begin{array}{l}0.92 \\
0.85\end{array}$ \\
\hline moult IV to last moult & $\begin{array}{l}0 \\
+\end{array}$ & $\begin{array}{l}1.00 \\
0.34\end{array}$ & $\begin{array}{l}0.95 \\
0.42\end{array}$ & $\begin{array}{l}2.80 \\
0.83\end{array}$ \\
\hline $\begin{array}{l}\text { Growth ( } \mu \text { m per day): } \\
\text { moult I to IV }\end{array}$ & $\begin{array}{l}0 \\
q\end{array}$ & $\begin{array}{l}48 \\
45\end{array}$ & $\begin{array}{l}49 \\
42\end{array}$ & $\begin{array}{l}54 \\
49\end{array}$ \\
\hline moult IV to last moult & $\begin{array}{l}0 \\
q\end{array}$ & $\begin{array}{l}20 \\
13\end{array}$ & $\begin{array}{l}32 \\
30\end{array}$ & $\begin{array}{l}67 \\
32\end{array}$ \\
\hline $\begin{array}{l}\text { Number of broods per female } \\
\text { Juveniles per female (sum) } \\
\text { Incubation time (days) }\end{array}$ & & $\begin{array}{l}3 \\
39 \\
16.0\end{array}$ & $\begin{array}{c}4 \\
30 \\
8.8\end{array}$ & $\begin{array}{l}3 \\
23 \\
10.0\end{array}$ \\
\hline $\begin{array}{l}\text { Sexual maturity of } q 9 \text { : } \\
\text { time (days) } \\
\text { moult No. } \\
\text { size (mm) }\end{array}$ & & $\begin{array}{c}142 \\
5 \\
6.7\end{array}$ & $\begin{array}{l}110 \\
5 \\
5.2\end{array}$ & $\begin{array}{l}69 \\
4 \\
4.4\end{array}$ \\
\hline
\end{tabular}

temperature-dependence of growth is much weaker during the period from moult $I$ to moult IV than in later life stages, and it is always more obvious in males than in females.

The pattern of growth is quite different if the average increase in body size per moult is analysed (Table 1): This second measure of growth decreases in both sexes with increasing temperature if only the first four moults are considered, but shows the opposite trend in later life stages. These influences cancel each other out if the whole life span is considered. In other words: Juveniles grow faster during each moult at lower than at elevated temperatures (this is also visible in the average daily length increment), while mature individuals show higher growth rates per moult if temperature is high.

The number of antennal segements can be used as a third index of growth (Table 2). At the time of the first moult there are in both sexes 5 segments in the first antenna, and 6 segments in the second antenna. Asymptotic growth is also visible in this case: Until moult IV the number of segments increases to 8 in the first, and to 7 in the second antenna; later only one segment per antenna is added. In sexually mature individuals of Jassa falcata constant numbers of antennal segments were always observed (Table 2).

The total numbers of moults observed were 5 to 6 in males, and 7 to 9 in females (Table 1). Lowest values were found at $20^{\circ} \mathrm{C}$. Moulting intervals in sexes were almost the same until sexual maturity was reached (Table 2). After this time, males only moulted 1 to 3 times, but females 3 to 4 times. Since moulting rate is always higher in females than in males, the higher size increment per moult observed in males as compared to females is 
Table 2

Jassa falcata: Growth (moulting stages, body length, number of segments in 1st/2nd antenna) and reproduction (brood size and duration of marsupial development) in laboratoy culture. Mean values and standard deviations (in parentheses)

\begin{tabular}{|c|c|c|c|c|c|c|c|c|}
\hline \multirow{2}{*}{$\begin{array}{c}\text { Moult } \\
\text { No. } \\
- \\
\end{array}$} & \multicolumn{2}{|c|}{$\begin{array}{l}\text { Time } \\
\text { (days) }\end{array}$} & \multicolumn{2}{|c|}{$\begin{array}{l}\text { Body length } \\
\text { (mm) }\end{array}$} & \multicolumn{2}{|c|}{$\begin{array}{l}\text { Antennal } \\
\text { segments }\end{array}$} & \multirow{2}{*}{$\begin{array}{c}\text { Juveniles } \\
\text { per female } \\
-\end{array}$} & \multirow{2}{*}{$\begin{array}{c}\text { Incubation } \\
\text { time (days) }\end{array}$} \\
\hline & $d^{\star}$ & q & 0 & q & $\theta$ & q & & \\
\hline & \multirow{2}{*}{\multicolumn{2}{|c|}{$40(6)$}} & \multirow{2}{*}{\multicolumn{2}{|c|}{$1.8(0.2)^{10^{\circ} \mathrm{C}}$}} & & & & \\
\hline 1 & & & & & \multicolumn{2}{|c|}{$5 / 6$} & - & - \\
\hline 2 & $62(2)$ & $62(2)$ & $2.8(0.1)$ & $2.6(0.2)$ & $6 / 7$ & $6 / 6$ & - & - \\
\hline 3 & $82(3)$ & $82(4)$ & $4.8(0.2)$ & $4.5(0.1)$ & $7 / 7$ & $6 / 7$ & - & - \\
\hline 4 & $120(4)$ & $120(3)$ & $6.8(0.1)$ & $6.4(0.3)$ & $8 / 8$ & $7 / 7$ & - & - \\
\hline 5 & $142(3)$ & $142(5)$ & $7.5(0.2)$ & $6.7(0.2)$ & $8 / 8$ & $8 / 7$ & $9(2)$ & $16(3)$ \\
\hline 6 & $221(3)$ & $173(4)$ & $8.8(-)$ & $7.2(0.1)$ & $9 / 8$ & $8 / 7$ & $23(6)$ & $17(4)$ \\
\hline 7 & - & $221(5)$ & - & $7.4(0.2)$ & - & $8 / 7$ & $7(2)$ & $15(1)$ \\
\hline 8 & - & 238 (1) & - & $7.9(0.1)$ & - & $8 / 7$ & - & - \\
\hline 9 & - & $246(-)$ & - & $8.1(0.2)$ & - & $8 / 7$ & - & - \\
\hline \multicolumn{9}{|c|}{$15^{\circ} \mathrm{C}$} \\
\hline 1 & \multicolumn{2}{|c|}{$19(2)$} & \multicolumn{2}{|c|}{$1.5(0.1)$} & \multicolumn{2}{|c|}{$5 / 6$} & - & - \\
\hline 2 & $51(4)$ & $51(3)$ & $3.4(0.2)$ & $3.2(0.1)$ & $6 / 7$ & $6 / 6$ & - & - \\
\hline 3 & $69(5)$ & $69(4)$ & $4.0(0.2)$ & $3.5(0.2)$ & $7 / 7$ & $6 / 7$ & - & - \\
\hline 4 & 91 (4) & $91(2)$ & $5.5(0.3)$ & $4.8(0.3)$ & $8 / 8$ & $7 / 7$ & - & - \\
\hline 5 & $110(3)$ & $110(4)$ & $6.0(0.2)$ & $5.2(0.1)$ & $8 / 8$ & $8 / 7$ & $5(2)$ & $8(2)$ \\
\hline 6 & $150(5)$ & $118(2)$ & $7.4(-)$ & $5.3(0.2)$ & $9 / 8$ & $8 / 7$ & $5(1)$ & $8(1)$ \\
\hline 7 & - & $126(2)$ & - & $6.0(0.3)$ & - & $8 / 7$ & $11(3)$ & $12(2)$ \\
\hline 8 & - & $150(4)$ & - & $6.5(-)$ & - & $8 / 7$ & $9(2)$ & 7 (1) \\
\hline 9 & - & $162(2)$ & - & $6.9(0.2)$ & - & $8 / 7$ & - & - \\
\hline & \multicolumn{8}{|c|}{$20^{\circ} \mathrm{C}$} \\
\hline 1 & \multicolumn{2}{|c|}{$18(2)$} & \multicolumn{2}{|c|}{$1.8(0.2)$} & \multicolumn{2}{|c|}{$5 / 6$} & - & - \\
\hline 2 & $40(3)$ & $40(4)$ & $2.8(0.2)$ & $2.5(0.2)$ & $6 / 7$ & $6 / 6$ & - & - \\
\hline 3 & $51(2)$ & $51(3)$ & $4.1(0.3)$ & $3.8(0.2)$ & $7 / 7$ & $6 / 7$ & - & - \\
\hline 4 & 69 (3) & 69 (2) & $4.7(0.2)$ & $4.4(0.1)$ & $8 / 8$ & $7 / 7$ & $5(2)$ & $10(3)$ \\
\hline 5 & 111 (4) & $96(4)$ & $7.5(0.3)$ & $5.2(0.3)$ & $9 / 8$ & $8 / 7$ & $9(3)$ & $11(2)$ \\
\hline 6 & - & $111(3)$ & - & $6.0(0.2)$ & - & $8 / 7$ & $9(4)$ & $9(1)$ \\
\hline 7 & - & $147(3)$ & - & $6.9(0.2)$ & - & $8 / 7$ & - & - \\
\hline
\end{tabular}

partly compensated. The maximum body size therefore is in general only slightly (1.1 times) larger in males than in females (Table 1). This relation was found at the three temperatures investigated. In both sexes the largest individuals occurred at the lowest temperature.

\section{Attainment. of sexual maturity}

The age and body size at which sexual maturity is attained by Jassa falcata is strongly influenced by temperature (Table 1 ): At $20^{\circ} \mathrm{C}$ the time to reach maturity ( 69 days) is about half the value observed at $10^{\circ} \mathrm{C}$. As observed in growth rates, the temperature influence is stronger between $10^{\circ}$ and $15^{\circ} \mathrm{C}$ than between $15^{\circ}$ and $20^{\circ} \mathrm{C}$.

Both sexes attain sexual maturity at the same moult and at approximately the same age, but at different body size: At $10^{\circ} \mathrm{C}$ the average body size in females is $6.7 \mathrm{~mm}$, but $7.5 \mathrm{~mm}$ 
in males. At $15^{\circ} \mathrm{C}$ the values are 5.2 and $6.0 \mathrm{~mm}$, and at $20^{\circ} \mathrm{C} 4.4$ and $4.7 \mathrm{~mm}$ (Tables 1 and 2). Not only the average body size, but also the difference between males and females is obviously temperature-dependent. Explanations for these observations can easily be deduced from the growth patterns described above.

\section{Mating behaviour}

Sexually mature males were observed to grasp mature females and to mount them, while the females mostly remain with their uropods adhering inside their tubes. In some cases males and females were observed swimming around in this precopulatory riding position.

At $15{ }^{\circ} \mathrm{C}$ the riding behaviour lasts for 2 to 3 days, then the female moults. Within 1 to $2 \mathrm{~h}$ thereafter, 2 to 3 copulations take place, after which the partners separate. Oviposition is performed 15 to $60 \mathrm{~min}$ after the last copulation.

\section{Incubation of eggs, hatching and number of offspring}

The time between oviposition and hatching of juveniles (incubation period) is approximately constant in the temperature range $15^{\circ}$ to $20^{\circ} \mathrm{C}$, but about 1.6 to 1.8 times longer at $10^{\circ} \mathrm{C}$ (Table 1). In contrast to Coropbium insidiosum (Nair \& Anger, 1979), the age of the female has no obvious influence (Table 2 ).

Liberation of juveniles from the marsupium was observed 10 to $30 \mathrm{~h}$ after hatching at $15^{\circ} \mathrm{C}$. The body size of freshly hatched juveniles varies between 0.9 and $1.2 \mathrm{~mm}$.

The number of eggs produced by a female in a single brood and the average incubation time (Table 2) are approximately equal at $15^{\circ}$ and $20^{\circ} \mathrm{C}$, but almost double at $10^{\circ} \mathrm{C}$. The age of the female has no clear influence; seemingly the last brood but one is the largest (Table 2).

The number of broods produced during the life cycle of Jassa falcata is 3 to 4 . The total number of offspring per female depends on temperature (Table 1): In our laboratory cultures increasing average values ( 23 to 39 juveniles) were found with decreasing temperature.

\section{DISCUSSION}

Jassa falcata is a suspension feeder exhibiting hardly any selectivity (DAHL, 1973). Therefore, it can be raised on different diets including detritus, algal matter, and planktonic animals. Similarly, as pointed out by Jażdżewski (statement cited by Dahl, 1973) for Gammarus species, $J$. falcata probably also changes its preferred diet during its individual development, becoming increasingly carnivorous. A mixture of zoo- and phytoplankton with detritus was found suitable for all life stages.

The average ingestion rate of adult $J$. falcata observed during 6-h intervals in preliminary experiments depends on the type of food and the frequency of renewing water and food: If the rotifer Brachionus plicatilis (size: ca. $150 \mu \mathrm{m}$ ) is given as prey, almost twice 
as many individuals per hour are eaten than if Artemia salina nauplii are provided. If water and food are not renewed during a $24-\mathrm{h}$ period, feeding rates on rotifers decrease due to decreasing prey concentration and possibly also due to deteriorating water quality. This was also observed in Corophium insidiosum (Nair \& Anger, 1979), but not when brine shrimp nauplii were given as food.

Females are significantly more resistent to starvation than males. This fact was also observed in C. insidiosum (Nair \& Anger, 1979); it can be explained by higher lipid reserves of the females which have to produce yolk mass for the eggs. Increasing temperature increases metabolism and hence, weakens starvation resistance.

The mortality pattern in a laboratory population, and with some likelihood also in natural populations, shows a bimodal distribution reflecting two different causes of mortality: In juveniles there are probably several factors such as lower resistance to unsuitable environmental conditions causing high mortality rates, especially during the first moult. Much later, physiological aging following the reproductive phase causes high mortality rates, especially during the last two moults. The same pattern was observed in $C$. insidiosum (Nair \& Anger, 1979).

At low temperatures $\left(10^{\circ} \mathrm{C}\right), J$. falcata shows a slow, long-continued growth; due to a prolonged life span, it attains a larger final body size. These trends have also been observed in other amphipod species in the colder parts of their distribution area (e.g. Stephensen, 1940), and in controlled laboratory experiments (Kinne, 1953; 1970). Growth patterns also influence the average body size and the time of attaining sexual maturity. General relationships between temperature, growth, maturation, length of life, and maximum size in amphipods have been discussed in detail by Kinne (1953).

Mating behaviour, incubation of eggs, brood protection, and liberation of juveniles are similar to many other amphipods (e.g. Schellenberg, 1942; Kinne, 1961 and earlier papers cited therein; Steele \& Steele, 1973; Krishnan \& John, 1974; Shyamasundary, 1976). In C. insidiosum, Nair \& Anger (1979) found some deviating characters in mating behaviour and in the period of brood protection after hatching of juveniles.

The number of offspring produced is influenced by temperature, but in our laboratory experiments it did not significantly change with age of the female. If a larger quantity of females were considered, a relationship between the size of a female and the number of eggs would be expected until the amphipod reached its maximum physiological age (Kinne, 1961).

In C. insidiosum, Nair \& Anger (1979) found that the age of the mother animal at the time of breeding influenced several life-cycle characteristics of its offspring (life span, number of moults, growth rate, number of broods and eggs, incubation period). In $J$. falcata such influence (if existing also in this species) could not be studied due to the slow growth and the long life span of this species. Further long-term cultivation, if possible combined with field studies, is necessary to increase the knowledge of this ecologically important amphipod species.

Acknowledgements. The first author is deeply indebted to Prof. O. Kinne, Director, Biologische Anstalt Helgoland (FRG), for providing working facilities at the Marine Station at Helgoland and also for the constant encouragement extended throughout the period of studies. He is grateful to Deutscher Akademischer Austauschdienst (DAAD) for financial support, and to Dr. S. Z. Qasim, Director, National Institute of Oceanography (C.S.I.R.), Goa (India), for his interest in this study and 
for allowing him to carry out this work on deputation. The authors wish to express their thanks to Dr. W. Greve and Dr. E. Hagmeier for supplying the original "seed" cultures of Brachionus plicatilis and Scrippsiella faeroense. Thanks are also due to Dr. I. Markham for correcting the manuscript and to all staff members of the Marine Station Helgoland who have helped from time to time.

\section{LITERATURE CITED}

Barnard, J. L., 1958. Amphipod crustaceans as fouling organisms in Los Angeles-Long Beach harbors, with reference to the sea-water turbidity. Calif. Fish Game 44, 161-170.

Dahl, E., 1973. Ecological range of Baltic and North Sea species. Oikos (Suppl.) 15, 85-90.

Daro, M. H., 1970. L'association des amphipodes et des Polydora ciliata à la côte Belge. Neth. J. Sea Res. 5, 96-100.

Ebling, F. J., Kitching, J. A., Purchon, R. D. \& Bassindale, R., 1948. The ecology of the Lough Ine rapids with special reference to water currents. II. The fauna of the Saccorbiza canopy. J. Anim. Ecol. 17, 223-244.

Kinne, O., 1953. Zur Biologie und Physiologie von Gammarus duebeni Lillj. Z. wiss. Zool. 157, $427-491$.

- 1961. Growth, moulting frequency, heart beat, number of eggs and incubation time in Gammarus $z a d d a c b i$ exposed to different environments. Crustaceana 2, 26-35.

- 1970. Temperature: Invertebrates. In: Marine ecology. Ed. by O. Kinne. Wiley-Interscience, Chichester, 1, 407-514.

Krishnan, L. \& John, P. A., 1974. Observation on the breeding biology of Melita zeylanica Stebbing, a brackish water amphipod. Hydrobiologia 44, 413-430.

Nair, K. K. C. \& Anger, K., 1979. Life cycle of Coropbium insidiosum (Crustacea, Amphipoda) in laboratory culture. Helgoländer wiss. Meeresunters. 32, 279-294.

Perkins, E. H., 1974. The biology of estuaries and coastal waters. Academic Press, London, 678 pp.

Ricketts, E. F. \& Calvin, J., 1968. Between Pacific tides. Stanford University Press, Stanford, Calif., $614 \mathrm{pp}$.

Schellenberg, A., 1942. Flohkrebse oder Amphipoda. Tierwelt Dtl. 40, 1-252.

Shyamasundari, K., 1976. Effects of salinity and temperature on the development of eggs in the tube building amphipod Corophium triaenonyx Stebbing. Biol. Bull. mar. biol. Lab., Woods Hole 150, 286-293.

Sokolowsky, A., 1900. Beiträge zur Meeresfauna von Helgoland. XI. Die Amphipoden Helgolands. Wiss. Meeresunters. (Helgoland) 4, 141-166.

Steele, D. H. \& Steele, V. J., 1973. The biology of Gammarus (Crustacea, Amphipoda) in the north western Atlantic. VII. The duration of embryonic development in five species at various temperatures. Can. J. Zool. 51, 995-999.

Stephensen, K., 1940. The amphipods of N. Norway and Spitzbergen with adjacent waters. Tromsø Mus. Skr. 3, 219-362. 